\title{
Geomarketing Analyses of the Città Fiera Mall
}

\author{
Tamara SERAJNIK ${ }^{1}$, Salvatore AMADUZZI ${ }^{2}$ and Gernot PAULUS ${ }^{1}$ \\ ${ }^{1}$ Carinthia University of Applied Sciences, Villach / Austria \\ ${ }^{2}$ University of Udine / Italy·salvatore.amaduzzi@uniud.it
}

This contribution was double-blind reviewed as full paper.

\begin{abstract}
Nowadays, it is very difficult to succeed in a world of competition and challenges, especially for malls. Città Fiera is a big mall, situated in the North-East of Italy, and it attracts all kinds of people. Therefore, it is very important to know which marketing strategy (e.g. advertisement) should be utilized in which municipality in order to attract specific visitor categories. The mall marketing department needs to have information (e.g. spatial distribution and potential of visitors) about the following visitor categories: housewives aged under 45, housewives aged over 45, employees aged between 35 and 55, unemployed and university students.

The paper is structured as follows: at first a basic overview about the topic is provided through a literature research. Then the interview data is analyzed, projecting the empirical 10.140 interviews to the total number of 5.248.441 yearly entrances counted at the door of the mall. Then, the statistical analysis is performed and the geodata are evaluated. Finally, network analysis and spatial analysis are carried out, as well as a subsequent cartographic visualization. Based on this analysis the marketing department knows who the visitors are and where they reside. It is subsequently possible to define the marketing strategy (e.g. advertisement) for specific visitor categories at the right location.
\end{abstract}

\section{Introduction}

Understanding the characteristics of the visitors is essential in order to succeed in a world of competition and challenges, especially for malls.

Città Fiera mall is located near the city of Udine, and it is the largest mall in the region Friuli-Venezia Giulia, in the northeast of Italy. Città Fiera is easily accessible with a very important traffic intersection nearby. It is accessible by a wide spread road system and has a linkage to the public transportation system, delivering over 30 buses to the mall per day. Città Fiera's offer is wide-ranging with over 200 stores, 15 multi-ethnic restaurants, a multiplex cinema, 2 play areas, a hypermarket, etc. It is a big mall, which offers opportunities for shopping, relaxing, eating, etc. The mall attracts various kinds of people. The visitors do not only come from the surrounding regions, but also from other countries, in particular Slovenia, Croatia or Austria. The mall has an area of more than 80.000 square meters. There is a project set to increase its surface area up to 160.000 square meters. The 
expansion will be done in steps and in the end Città Fiera will become the 4th or 5th largest mall in Europe (CORIO N.V. 2013, DEC S.P.A. 2011, DEC S.P.A 2012).

The marketing department of Città Fiera interviewed 10,410 people entering or leaving the mall in order to get an overview about the people's characteristics. With this empirical interview data the mall wanted to get a comprehensive understanding of the visitor's characteristics, and the spatial distribution of the location of their residences. Using the frequency of visits declared in each interview, and knowing that the door counters give a total number of 5.248.441 entries in the mall, it has been statistically calculated that 112,184 is the number of single visitors per year. With the help of spatial analyses, the marketing department of Città Fiera wanted to gather information about who the visitors are and where the visitors come from. This analysis should help the mall to decide on the specific marketing strategy (e.g. advertisement) and its spatial focus in order to attract specific visitor categories.

The Cittá Fiera is a complex mechanism that is growing constantly and, therefore, it is necessary to have an overview of the visitors.

It is important to know:

- Who the visitors are ((country of origin, including Italy, Austria, Slovenia, etc.), their occupation (e.g. students, employees and pensioners), etc.)?

- Where they come from (municipality or driving time area)?

Therefore it is essential to have information about:

- The visitors themselves (collected through empirical interviews)

- The residence locations of the mall's visitors (statistical socioeconomic data of municipalities)

Additionally, the marketing department of the mall wants to have information about the following visitor categories: (a) Housewives aged under 45; (b) Housewives aged over 45; (c) Employees aged between 35 and 55; (d) Unemployed; and (e) University students.

\section{Theoretical Background}

\subsection{Definition and application of geomarketing}

Geomarketing extends the classic marketing-mix, which consists of product, price, distribution and communication, with the spatial view. This is important because the market is different in different regions. With the help of Geographic Information Systems (GIS) and geodata it is possible to extend all internal data of a company, like customer information, with geographical coordinates, and combine it both with market and potential customer data. When visualized on a map, this combined information about the market achieves a new transparency (the company knows where its customers are situated, etc.) (BUCHER GRUPPE 2010).

One important advantage is that a company can see the data originally organized in tables, now visualized on a map. Doing so makes it possible to recognize spatial correlations between customer characteristics and market potential or finding spatial patterns in customer behaviour. Simply said, geomarketing is the optimization of marketing and sale with the help of GIS (TAPPERT 2007). 
In general, geomarketing can answer the following exemplary listed questions:

- What is the socio-demographic profile of the population?

- How much demand is available for the offered product lines?

- Are there one or more customer groups?

- How high is the total sales potential (GFK GEOMARKETING GMBH 2012)?

\subsection{Best practise projects: GIS-based geomarketing analysis}

For a mall, it is very important to know who its customers are and how they behave. The various customer groups and their characteristics are of special interest for the understanding of the customer needs. Therefore, the next paragraph shows some exemplarily listed projects, classified according to a research topic.

\section{Trade area/catchment area analysis}

In the study of HOMBERGER \& PARTNER STANDORT MARKETING (2012) a site analysis of the mall Stadion Schaffhausen, Schwitzerland, was conducted. In the study of SuSHKOV(2009) driving zones were defined depending on drive or walk time, and analyses about the demographic characteristics of catchment areas were conducted, etc. KRIEGER (2011) calculated catchment areas (10 and 15 minutes driving time) for the mall Sonnenhof, Switzerland. THE CENTER FOR SPATIAL RESEARCH (2010) conducted a geomarketing analysis of the mall's trade area, containing the calculation of various drive and walking time areas in order to get an idea about the number of visitors, the possible future revenue and the level of purchasing power of the mall located in St. Petersburg, Russia.

\section{Spatial customer analysis of mall visitors}

The study of MURAD (2005) shows how to determine if and how GIS can be used in retail planning. The author conducts various analyses, such as the calculation of the proximity to the retail center, the spatial interaction between the center and the retail demand and the characteristics of the customers for the Oasis Mall in Jeddah City, Saudi Arabia.

\section{Customer behaviour analysis and profiling of mall visitors}

In the study of ANURADHA \& MANOHAR (2011) 93 customers of two different shopping malls were interviewed (City Centre Mall and Express Avenue Mall of Chennai, India), in order to get an insight of the role of different variables (external and internal) influencing for example the shopping behaviour of customers. In the study of KURUVILLA \& NISHANK (2009) the customer behaviour of Indian people was studied. The purpose of the project was, for example, to profile the customers of Indian malls using demographic attributes, purchase patterns, shopping behaviour, etc. and to examine the differences in shopping orientations, demographics, frequency of visits, etc.

\section{Data Analysis}

The following list entails and describes the data available for the analyses.

\section{Empirical interview data of mall visitors (the interviews were conducted by the marketing department of the mall itself in 2012)}

The marketing department of the Città Fiera mall interviewed the mall visitors entering and leaving the mall (on weekends and during the week). The interviews were conducted in 3 weeks in May, June and July 2012. The visitors were asked about their age, gender, 
occupation, studies, number of family members, reason of their visit (Which shops they will visit or have visited today?, Which shops they usually visit?), home town (municipality), other malls visited, etc. 10,410 people were interviewed in total, and 24 different variables were collected.

\section{Projection of the empirical interview data}

In a next step, the number of visitors interviewed was projected to the number of visitors for a one year total. This projection was done by the University of Udine using the MARKETFINDER geomarketing tool. The number of interviews and their answers were analysed using the total entries counted by the door entries counters (5.248.441) per year. The declared frequency of visits per interview was used to evaluate the total number of entries of the interviewed people in one year (509.539). Using this information and the total number of entries in one year, the approximate number of visitors per year was calculated $(112,184)$.

Socioeconomic statistical data from Istat (Italian National Institute of Statistics) in 2011 Socioeconomic data are data about the population and the economy. The data from 2011 were received from Istat. The data cover the whole of Italy, Slovenia and Austria at a municipality level. 59 variables are available in the data set, showing for example the number of women and men, the number of employed people, housewives, total income, etc.

Administrative borders (received from Istat for $\mathbf{2 0 1 2}$ and from CloudMade for 2011) The administrative borders were, on the one hand, collected from Istat, and, on the other hand, downloaded from CloudMade (OSM (Open Street Map)-data) for the areas of Italy, Slovenia and Austria (ClOUdMAdE 2011).

\section{Street data (from Nokia from 2012 and from Geofabrik from 2013)}

The street data for the project area was, on the one hand, received from Nokia (Navteqdata) for the area of Friuli-Venezia Giulia, and, on the other hand, downloaded from Geofabrik (OSM-data) for the area of Europe (GEOFABRIK 2013). This data has been used to calculate the isochrones.

\section{Methodology}

Figure 1 shows a flow chart detailing the data input, analysis concept and results.

The data used in this project are the empirical interview data set of mall visitors, the statistical socioeconomic and spatial data at the municipality level, and the street data from Open Street Map and Navteq. At first a descriptive statistical analysis of the empirical interview data of mall visitors is completed. In order to use the data for any further analysis, the number of interviewed people (10.410 people) is projected to the number of people visiting the mall in one year. This is done in order to match the data with the data from the municipalities. It is also important to create driving time areas. Based on the street network (network analysis) 10 to 90 minute isochrones are generated with an interval of 10 minutes (see figure 2). All relevant data are subsequently joined (spatial analysis), and, as a result, the spatial visitor distribution per driving time area is generated (see figure 3).

Also thematic maps are created in order to visualize a spatial distribution of the visitors. 


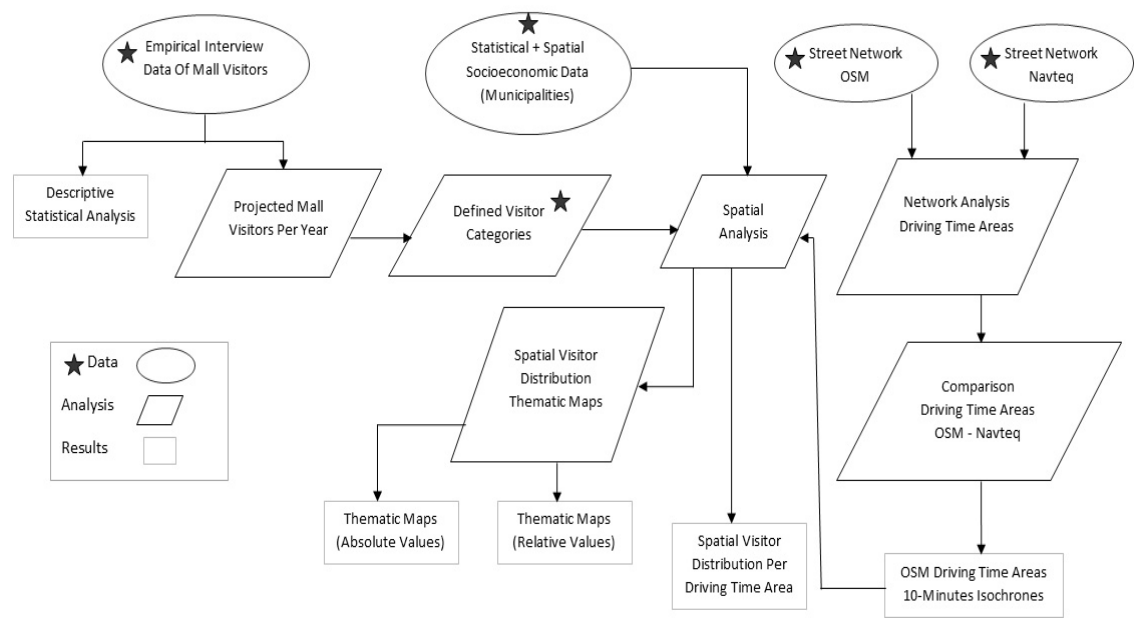

Fig. 1: Flow chart of the method of solution

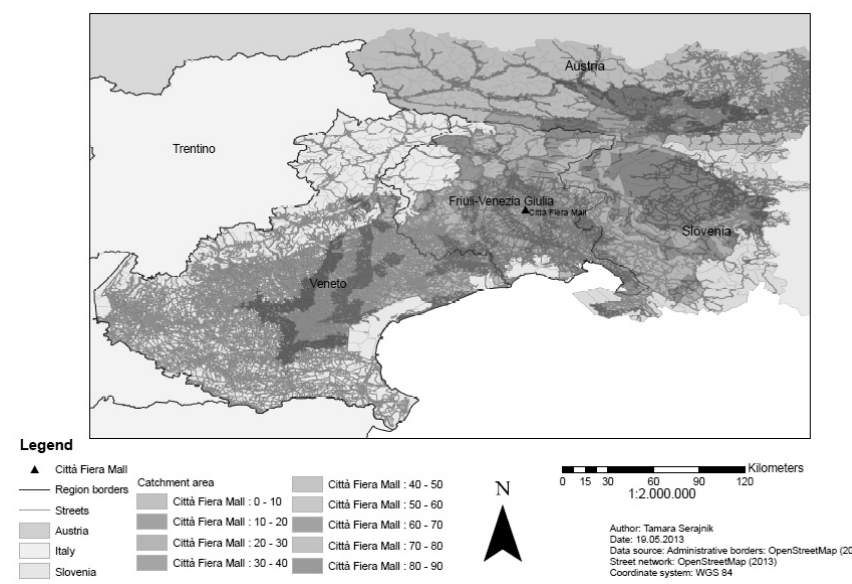

Fig. 2:

Example map of catchment areas based on driving time

$\%$ visitors per isochrone under 90 minutes on total number of visitors coming from Italy

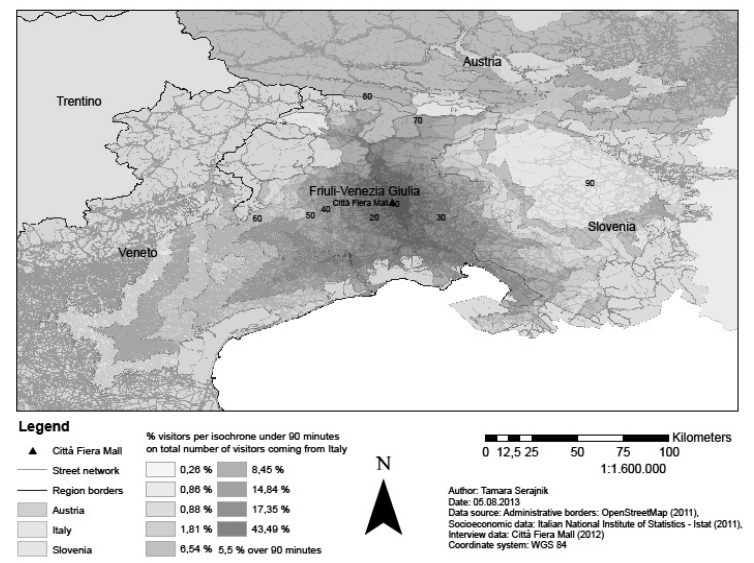

Fig. 3:

Example thematic map of the isochrones on the total number of visitors 


\section{Results}

In this section, the results of the analysis are described in detail. Further results in the form of thematic maps, are listed on an exemplarily chosen visitor category.

\section{Descriptive statistics}

The results of the descriptive statistics show the basic statistical description of the empirical interview data. Calculated are the mode, mean, median, standard deviation, variance, range, and percentile of the variables day, week period, door entrance, gender, municipality, province, region, nation, highest level of education, occupation, frequency of visits, what stores did were visited on the interview day, what stores are usually visited, other malls visited, interviews, time, age, and number of family members, which are divided into nominal and metric scale.

Also, the frequency and percentages of specific characteristics of the visitors, as deemed to be important by the geomarketing department of the mall, are calculated (gender, age groups, frequency of visits, occupation, nation, housewives and employed people aged between 35 and 55). Bar and pie charts visualize the main variables in percentages to provide a better overview. The charts show the percent distribution of some characteristics (gender, age groups ( 0 till 14, 15 till 18, 19 till 30, 31 till 45, 46 till 60 and >60), frequency of visits (daily, weekly, monthly, etc.), occupation (students, housewives, etc.), nation, education level, week period, and what stores were visited a) on the interview day, and b) usually) of the visitors. The descriptive statistics provide a comprehensive understanding of the visitor characteristics.

The next results were gained from the spatial analysis part of this project.

\section{Distribution of visitor categories per driving time areas}

With the help of isochrones it is possible to understand what kinds of visitors are living in which driving time area. In the diagram below (see figure 4), the visitor categories are shown using driving time and number of visitors. This allows a better insight into the distribution of the visitors across the isochrones. The most visitors are coming from the driving time area of less than 10 minutes.

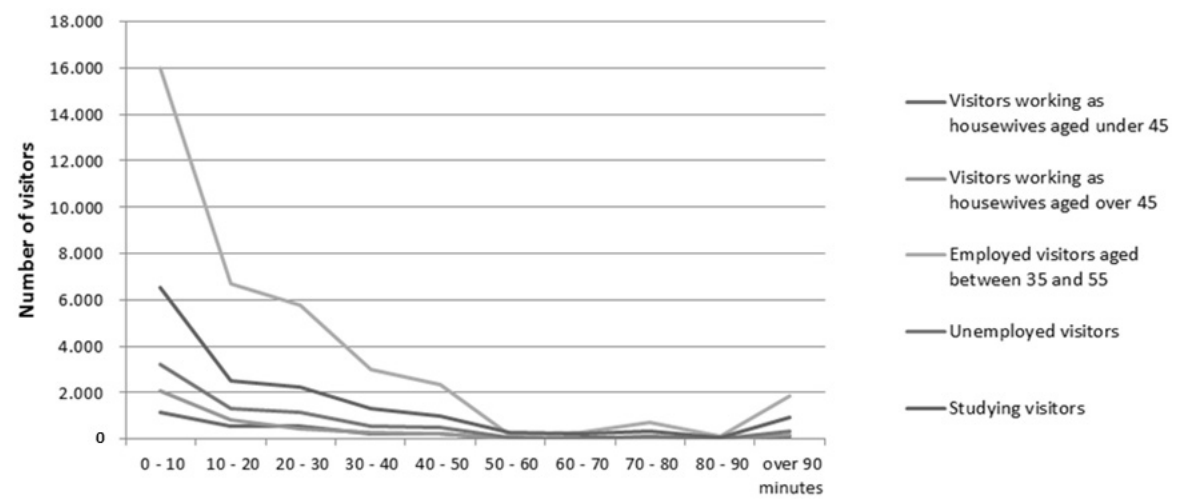

Fig. 4: Città Fiera Mall: number of visitor per category and isochrones 
As can be seen in figure 4, students represent the second largest group among the analysed visitor categories. For this reason, the next results are shown exemplarily for the student visitor group.

\section{Spatial distribution of students}

Thematic maps provide the spatial distribution of the visitor categories. Different types of maps were generated. The first type (not shown here) represents the absolute number of visitors with a specific characteristic per municipality, namely the number of student visitors per municipality. The second map shows the percentages of visitors with a specific characteristic over all residents per municipality, namely the percentage of student visitors over all residents per municipality (see figure 5). The dark colours represent those municipalities where a higher percentage of student visitors are coming from.

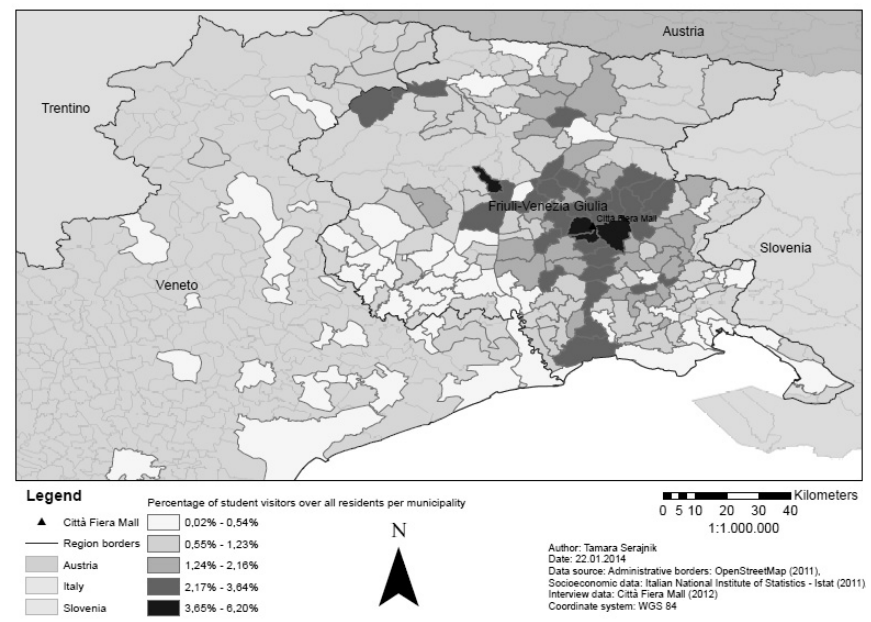

Fig. 5: Percentage of student visitors over all residents per municipality

The third type of map shows the percentage of visitors with a specific characteristic over all residents with the same characteristic per municipality, namely the percentage of student visitors over all student residents per municipality (see figure 6).

For some maps (depending on the visitor category) bipolar colouring is used to allow an appropriate visualisation of the information. In general, blue colours show low values and red colours show high values. Values just below and above 100\% (from 95\% - 105\%) are shown in white. However, the percentages of some municipalities are even above $105 \%$, which is not possible. Those municipalities are shown in red and they need to be looked into in more detail in future research.

\section{Potential of visitor categories per municipality}

The market potential of every visitor category per municipality was also calculated. The market potential shows the number of people who have not yet visited the mall. The market potential is calculated as the difference between the total number of residents with a specific characteristic and the number of those residents having actually visited the mall before. The market potential was calculated for all visitor categories and the results were tabulated and visualised in maps. The following map shows the market potential of student 
visitors per municipality (see figure 7). It shows those municipalities where less than $52.94 \%$ are student visitors over all student residents per municipality, and so an increasing potential of about $50 \%$ is shown. In numbers, it shows a potential from about 9 to 13,724 people who have not yet visited the mall.

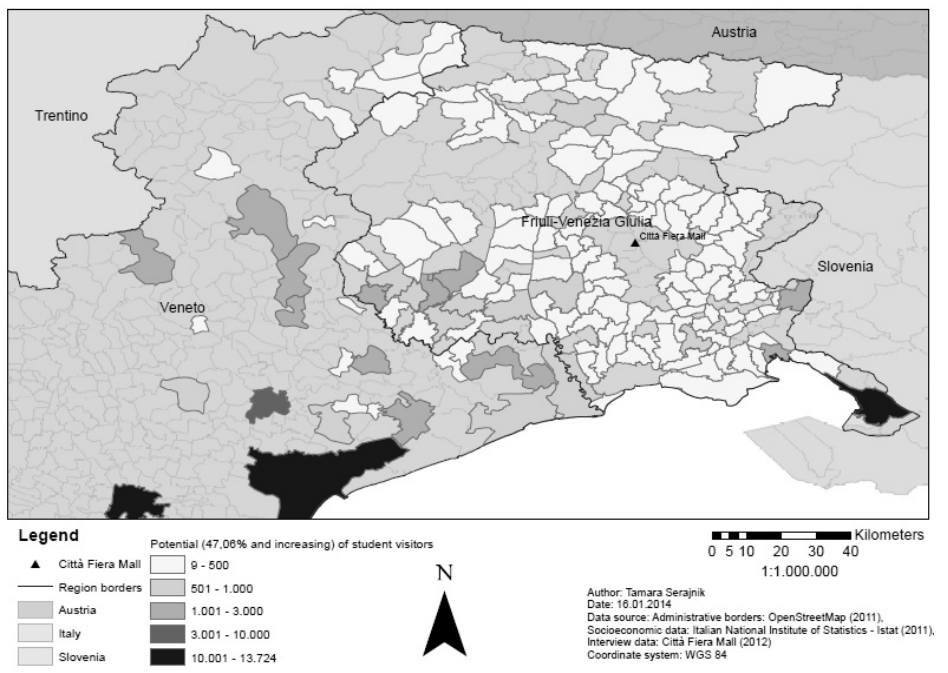

Fig. 6: Percentage of student visitors over all student residents per municipality

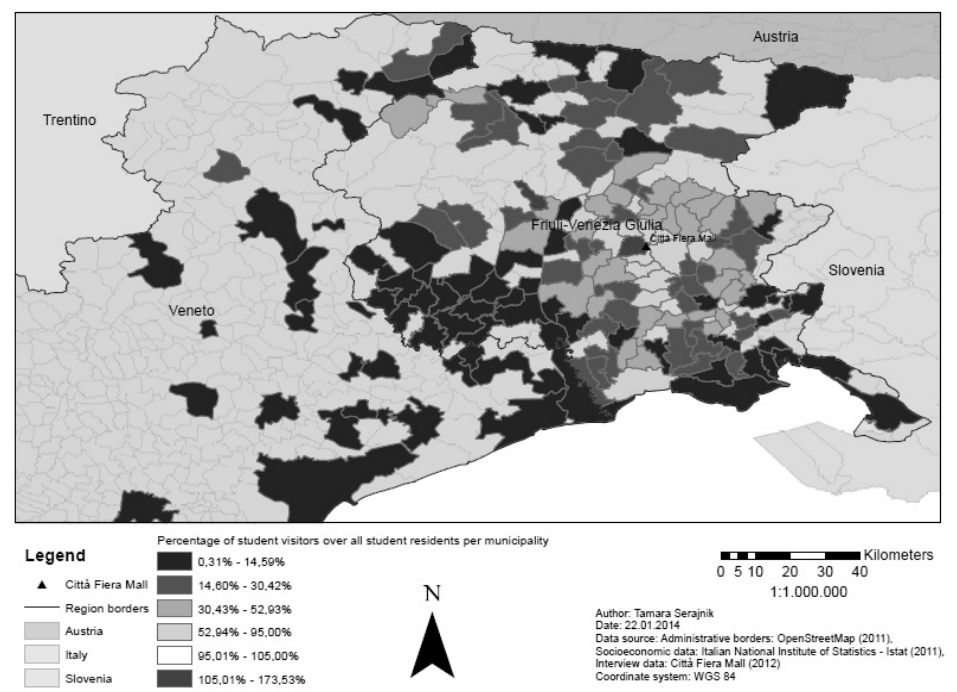

Fig. 7: Potential of student visitors per municipality

Maps about market potential for the different visitor categories were generated to locate the municipalities with high market potentials. Thus, the mall's marketing department is able to advertise to specific visitor categories at the correct municipalities. 


\section{Conclusion and Outlook}

In this project, a basic overview about the available data was explored with the descriptive statistics. This provided a comprehensive understanding of the visitor's characteristics. With the help of isochrones it was possible to combine the visitor categories with specific driving time areas. This allowed for a better insight into the distribution of the visitors across isochrones.

Thematic maps were then used to visualize the spatial distribution of specific visitor categories. Three different types of thematic maps show (1) the number of visitors with a specific characteristic per municipality; (2) the percentage of visitors with a specific characteristic over all residents per municipality, and (3) the percentage of visitors with a specific characteristic over all residents with the same characteristic per municipality.

The maps help the marketing department of the mall to understand how many and which kind of visitors are coming from which municipalities.

Also, the market potential was calculated for all visitor categories for each municipality. The market potential shows the number of people who have never visited the mall and can be calculated as the difference between the total number of residents with a specific characteristic and the number of those residents having actually visited the mall before. Maps of the market potential for the visitor categories were generated to locate the municipalities with a high market potential. In so doing, the mall is able to advertise for specific visitor categories at the right locations.

For future research it will be necessary to look at how the projected data were calculated in order to improve the quality of the corresponding results. In some cases (percentage of student visitors over all student residents for all municipalities; the percentage of unemployed visitors over all unemployed residents for all municipalities) it is obvious that the projected numbers are incorrect, since more than $100 \%$ of the residents of a particular municipality for a specific characteristic should have visited the mall.

Another future research avenue may be to analyse the income of the shops in the mall, and to compare it to the income of people living in the municipalities. The income information is entailed in the socio economic data base acquired, and the shops' incomes are easy to obain by the mall organisation. An interesting aspect for future research could be to create a Web GIS for the mall. This way, it would be possible to see the most important information about the mall in an interactive display. Additional interviews could be easily included with the existing ones, by simply loading the original interview data and the additional interviews on the Web Server. Also, visualisations in the form of maps could provide specific information about the visitors' characteristics by simply clicking on the municipality of interest. The Web GIS should be configured as simple as possible in order to easily manage the information about the visitors' characteristics and to add new data, etc. In this way, the marketing department of the mall would also be able to use the Web GIS.

\section{References}

AMADUZZI, S. (2011), GEOMARKETING. I SIT-GIS a supporto delle aziende e della pubblica amministrazione. EPC editore, Roma. 
ANURADHA, D. \& MANOHAR, H. L. (2011), Customer shopping experience in malls with entertainment centres in Chennai. African Journal of Business Management, 5, 23192324: http://www.academicjournals.org/ajbm/pdf/pdf2011/7Dec/

Anuradha\%20and\%20\%20Manohar.pdf (4/2013).

BUCHER GRUPPE (2010), Geoinformatik, Tennesee: Books LLC, Wiki Series.

CloudMade (2011), CloudMade. http://downloads.cloudmade.com (27.02.2013).

CORIO N. V. (2013), Città Fiera, Udine, Corio. http://www.corio-eu.com/79/dealer/ citta_fiera_udine.html?coords=41.8954656 (22.02.2013).

DEC S.P.A. (2011), Centro Commerciale Città Fiera. www.cittafiera.it: http://www.cittafiera.it/english/contact-us (05.01.2014).

- (2012), Centro Commerciale Città Fiera, from www.cittafiera.it: http://www.cittafiera.it/english/development-areas (05.01.2014).

GEOFABRIK (2013), Geofabrik. http://download.geofabrik.de/openstreetmap/europe/ (08.03.2013).

GfK GeOmarketing GmBH (2012), Geomarketing in Practice. Retrieved from Information for RegioGraph users: http://www.gfk-regiograph.com/fileadmin/regiograph_en/ customer_support/geomarketing_in_practice_compact.pdf(17.11.2012).

Homberger \& PARTNER StANDORT MARKETING (2012), Standort Analyse Einkaufszentrum Stadion Schaffhausen "Herblingertal”. FCS Park Schaffhausen. http://www.fcspark.ch/Portals/0/Dokumente/Homberger\%20-\%20Standortanalyse.pdf (11.03. 2013).

KRIEGER, D. (2011), Die Revitalisierung von Shopping-Centern - Inhalt, Verfahren und Potential. Masterthesis, Universität Zürich. http://www.bf.uzh.ch/curemapplications/masterthesen/2011/Krieger_David_MT_2011.pdf. (11.03.2013).

Kuruvilla, S. J. \& Nishank, J. (2009), Profiling the Heavy Consumers at Malls in India: Influence of Demographics, Shopping Orientations, Selected Psychographic Dimensions, Image Perception and Attribute Importance on Mall Patronage. 3rd IIMA Conference on Marketing Paradigms for Emerging Economies, 32-36. http://www.cfriima.org/abstracts/2009/Kuruvilla,\%20Shelja\%20Jose\%20and\%20Joshi,\%20Nishank\% $20 \% 20$ Profiling $\% 20$ the $\% 20$ Heavy $\% 20$ Consumers $\% 20$ at $\% 20$ Malls $\% 20$ in $\% 20$ India $\% 20$ Influence\%20of\%20Demographics.pdf (06.04.2013).

MuRAD, A. A. (2005), Using geographical information systems for exploring demand on retail centers at Jeddah city. http://ieeexplore.ieee.org/stamp/stamp.jsp?tp=\&arnumber=1500254\&isnumber $=32161$ (09.03.2013).

SushKov, S. (2009), Shopping Mall Trade Area Analysis. http://de.slideshare.net/decemberstar55/shopping-mall-trade-area-analysis (10.03.2013).

TAPPERT, W. (2007), Geomarketing in der Praxis: Grundlagen - Einsatzmöglichkeiten Nutzen. Karlsruhe, Bernhard Harzer Verlag.

The Center for Spatial Research (2010), Recently Completed Project: Geomarketing Analysis of the Shopping Mall Trade Area. The Center for Spatial Research. http://csrgeomarketing.com/recently-completed-project-geomarketing-analysis-of-theshopping-mall-trade-area/ (10.03.2013). 